\title{
Differentiated Demand and Supply Chain Planning of Fresh Meat Products: Linking to Animals' Lifetime
}

\author{
Flemming M. M. Christensen ${ }^{1}$, Iskra Dukovska-Popovska ${ }^{1} \&$ Kenn Steger-Jensen ${ }^{1,2}$ \\ ${ }^{1}$ Centre for Logistics (CELOG), Department of Mechanical, Manufacturing and Management \\ Engineering, Aalborg University, Denmark \\ fmmc@make.aau.dk \\ ${ }^{2}$ Faculty for Technology and Maritime, Department of Maritime Technology, Operations and \\ Innovation, University College of Southeast Norway, Norway
}

\begin{abstract}
Demand and supply chain planning of meat products with short shelf life is studied in a Danish wholesaler case. Main findings are that the lifetime of animals influences information sharing in planning, and differentiating planning according to demand characteristics influence supply chain negatively. This study suggests lifetime-dependent differentiation in timeliness and frequency in sharing of information to enhance supply chain effectiveness and efficiency.
\end{abstract}

Keywords: Differentiation $\cdot$ Animal lifetime $\cdot$ Fresh meat $\cdot$ Demand planning

\section{$1 \quad$ Introduction}

Due to meat products' short shelf life, the risk of waste from expired products, due to poor planning and derived stock building, is large [1]. Meat products have a timedependent scarcity, as their raw materials (i.e. animals) have different time between birth and slaughtering/catching. Since fresh meat products are unfit for storing, and high availability influences consumer loyalty [2], efficient, effective and differentiated demand and supply chain planning is paramount. In particular for wholesalers, linking shops with upstream supply chain by consolidating and balancing the converging and diverging demand and supply flow.

Current planning frameworks tends to focus on information sharing between the producer and customer [3], and, internal planning at product group level [4-6], differentiated through forecasting-, production strategy- and/or inventory management-oriented segmentation [7] (e.g. order characteristics (lead-time, shelf life, temperature etc.) and demand characteristics (seasonality, fluctuation, frequency etc.) [7-11]). This influences wholesaler' effectiveness and efficiency inappropriately. Since wholesaler has no control of producing the products [11], the products have short time from order dispatch to order arrival and are unsuitable for storing, and, the raw materials have large differences in growth time, there are the different requirements to timeliness and frequency of information sharing. The second largest discount retail chain in Denmark and its wholesaler operates with hundreds of different meat products, segmented only per demand characteristics. It is thus relevant to investigate how demand and supply chain

adfa, p. 1, 2011 .

(C) Springer-Verlag Berlin Heidelberg 2011 
planning could differentiate and what is its effect on information sharing and frequency. By comparing wholesaler's planning approach against different raw materials' lifetime, it is possible to identify how demand and supply chain planning should include the differentiating aspects. Focus is on fresh meat products with up to 14 days shelf life. The following presents this study' framework about animal lifetime and demand planning time-horizon, then methodology, case study, analysis, discussion and conclusion.

\section{Theoretical Background}

Demand and supply chain planning aims to predict the future demand and supply, and respond upon this by sharing information and initiating different upstream activities accordingly and timely, to effectively and efficiently meet demand instantly when occurring $[11,12]$. Particularly for meat products, understanding demand and sharing information timely is needed due to the bullwhip effect [13] and constant degradation.

A key factor for improving supply chain operations is improving forecasting [14], which in turn creates a cost-effective supply chain [15]. For this purpose, products are usually grouped according to demand characteristics (e.g. steady, seasonal and promotional) with different efforts needed in forecasting and levels of supply chain collaboration [14]. The accuracy of forecasting is affected by time-horizon to forecast. The shorter time-horizon, the greater accuracy and reliability, hence, the lower risk and errors [8]. However, fresh meat products are influenced by scarcity after a certain point in time (i.e. when time to produce raw materials for slaughtering exceeds the forecast horizon). Hence, demand planning must be closely related with supply planning, since raw materials are living animals with different growth time. Table 1 shows the time it takes to grow different animals ready for slaughtering/catching, according to Danish Agriculture and Food Council. Clearly, the different meat types differ, from growth time of around one month for chickens to more than 24 months for beef, to catching fish according to size (influenced by nature and climate).

Table 1. Age \& Size of Animals Ready for Slaughtering \& Catching

\begin{tabular}{cccc}
\hline Beef & Pork & Chicken & Fish \\
\hline$<10$ months (veal) & $\approx 5-6$ months & & $>40-60 * \mathrm{~cm}$ (salmon) \\
$10-24$ months (young cattle) & $(90-105$ kilos) & $\approx 40$ days & $>25-27 * \mathrm{~cm}$ (flounder) \\
$>24$ months (cow-beef) & & $>30-35^{*} \mathrm{~cm}$ (cod) \\
\hline *depends on catching area (e.g. North Sea, Baltic Sea, Kattegat) and sea (salt- or freshwater)
\end{tabular}

Combined with the shelf life, fresh meat products' total lead-time differs largely from other food products. The total lead-time (growth, production and shelf life) of meat products, compared against a different food product, canned food, is illustrated in Figure 1. Canned food has relatively short growth time and long shelf life and may thus be handled (more or less strictly) in terms of inventory level and capital costs, due to the derived suitability for make-to-stock planning. Oppositely, fresh food has short shelf life with large growth time (animals' lifetime) and cannot be stored for more than few days (i.e. no stock building), meaning it must be handled in terms of risk of waste from poor planning, making it suitable for make-to-order planning. 


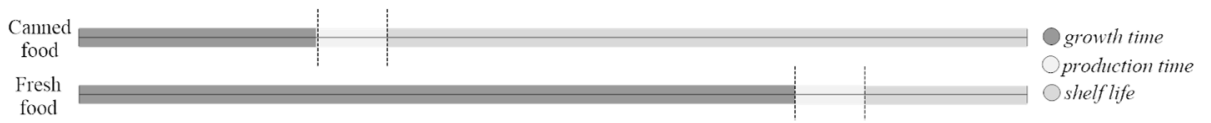

Fig. 1. Complete Lifetime of Different Product Groups

\section{Methodology}

This paper follows the explorative and empirical case study research approach of Flynn's six-stage design framework [16]. After investigating the current level of collaboration and differentiation in demand and supply chain planning, the purpose is to propose a differentiated planning approach that includes the raw materials' growth time. The ultimate goal of the approach is to meet consumers' requirements for availability. Since the product type and context is of particular importance in this case, studying in-depth in natural context enhances the insight and understanding of experiences $[17,18]$. Four different meat types from 16 different suppliers, supplied by one of the largest wholesalers in Demark, are in focus in order to provide a generalizable view of differentiation in demand planning. Due to reasons of commercial confidentiality, the company' identity will not be revealed and called ABC throughout this article. This study uses information obtained through semi-structured interview with product manager and purchaser evolving from standardized questions about demand planning. The study focuses on products with less than 14 days shelf life for beef (veal/young cattle/cow), pork, chicken and fish.

\section{$4 \quad$ Case Study}

ABC (part of Scandinavia's biggest company within grocery and service trading) uses a centralized warehouse to supply the Danish market (almost 300 shops). ABC's overall goal is to be "the most value-driven company in Scandinavia", and they measure performance mainly through service level. In 2016, ABC sourced 53 beef products from five suppliers, 45 chicken products from two suppliers, 70 pork products from seven suppliers and 33 fish products from two suppliers, with down to 36 hours from order dispatch at shop to delivery. ABC uses a so-called "transit"-flow where products are ordered six days per week, in exact amounts, with no stock keeping. Depending on whether the shops order normal (i.e. assortment) or campaign products, $\mathrm{ABC}$ receives shops' orders at latest 18:00 two days or four weeks before delivery, respectively. ABC aggregates and sums up all incoming orders, and forwards these to respective suppliers. Shops are allowed to add additional supplementing orders or change existing orders down to two days before delivery. At the end of the year, ABC shares information with suppliers about total expected sales for upcoming year (including expected growth and expanding) as well as category/assortment changes. For campaigns, forecasted demand is sent to suppliers around three months before campaign start through a tendering-like process. If several suppliers are chosen to deliver the products, $\mathrm{ABC}$ splits the demand 
according to available capacity at supplier's site, price, quality level and delivery degree. No further demand information is shared, and the suppliers use historical incoming orders from $\mathrm{ABC}$ in their internal demand planning. Figure 2 shows $\mathrm{ABC}$ ' planning cycles and information sharing, with activities for normal sale shown above the timeline and for campaign sale, below the timeline.

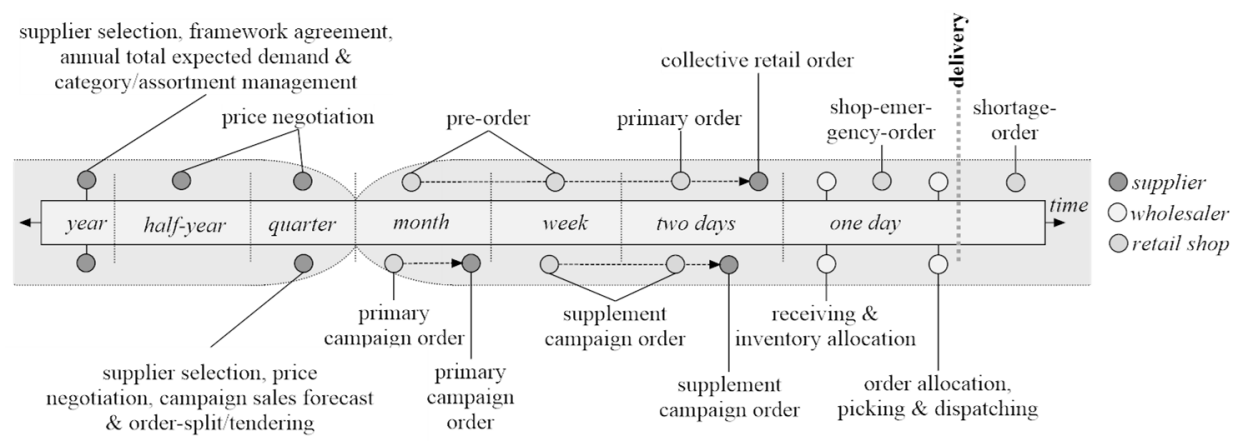

Fig. 2. Time Continuum for Planning Activities

\section{$5 \quad$ Analysis}

At overall level, ABC shares expected total annual demand (i.e. campaign and normal) for the upcoming year in November/early December. At lower level, the sharing differs, depending on whether it is campaign or normal demand. Campaign demand forecast and real orders are shared respectively three months and four weeks in advance for all products, allowing suppliers time to source raw materials needed (due to the larger demand). For normal demand, ABC expects suppliers to meet demand with two days' notice and does not share any information. The different meat types' lifetime characteristics influence the supply chain performance. Figure 3 shows timelines for each meat type with months back in time from the order dispatch, indicating the different times of information sharing between $\mathrm{ABC}$ and suppliers - relative to animals' life time and when they are given birth. The yellow area indicates the time it takes to raise animals until slaughtering back in time, while the blue area represents the time-window available for giving birth to the animals in order to have the animals ready for slaughtering and order dispatch.

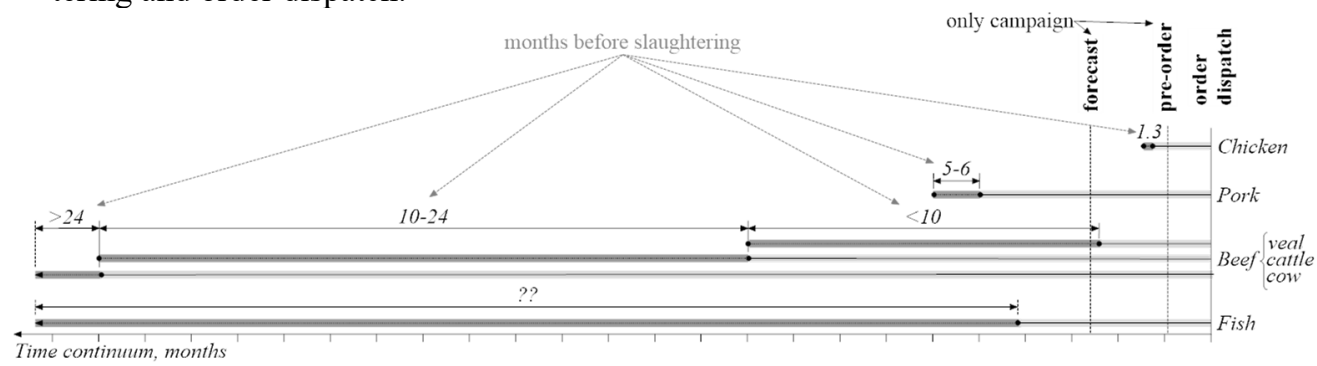

Fig. 3. Time Continuum for Planning of Meat Products versus Lifetime of Animals, in Months 
Cleary there is inconsistency between $\mathrm{ABC}$ ' uniform approach in information sharing with the suppliers and the time it takes to raise animals. For chickens campaign forecast is shared almost two months before they are born, which increases the noise in the supply chain due to premature information sharing and increases the forecasts errors due to untimely sharing of forecast. Instead, demand information should be shared at the time where the chickens need to be born, i.e. 40 days before order dispatch, meaning down to 42.5 days before order arrival in shops (when including the 36 hours from order dispatch in shop until arrival of order). This principle of lifetime dependent timely sharing of forecast also applies for other fresh meat types. For pork, beef and fish, the current approach means that forecast is shared months/years after animals are born creating a latent scarcity in availability of raw materials, deriving increased risk of not being able to source raw materials. This also means that upstream stages initiate production of animals according to isolated forecast, not driven by demand, meaning guess based forecasting with increased errors. In particular, fish are caught (and slaughtered) according to size and are heavily influenced by nature and climate, requiring forecasting longer time in advance to avoid unavailability. Hence, all meat types, but chicken, require relatively high level of collaboration and information sharing, i.e. timely demand planning. Figure 4 shows the animals available as raw material upstream in the supply chain (farmer stage) in relation to their lifetime planning window for slaughtering (after which they become unfit for use).
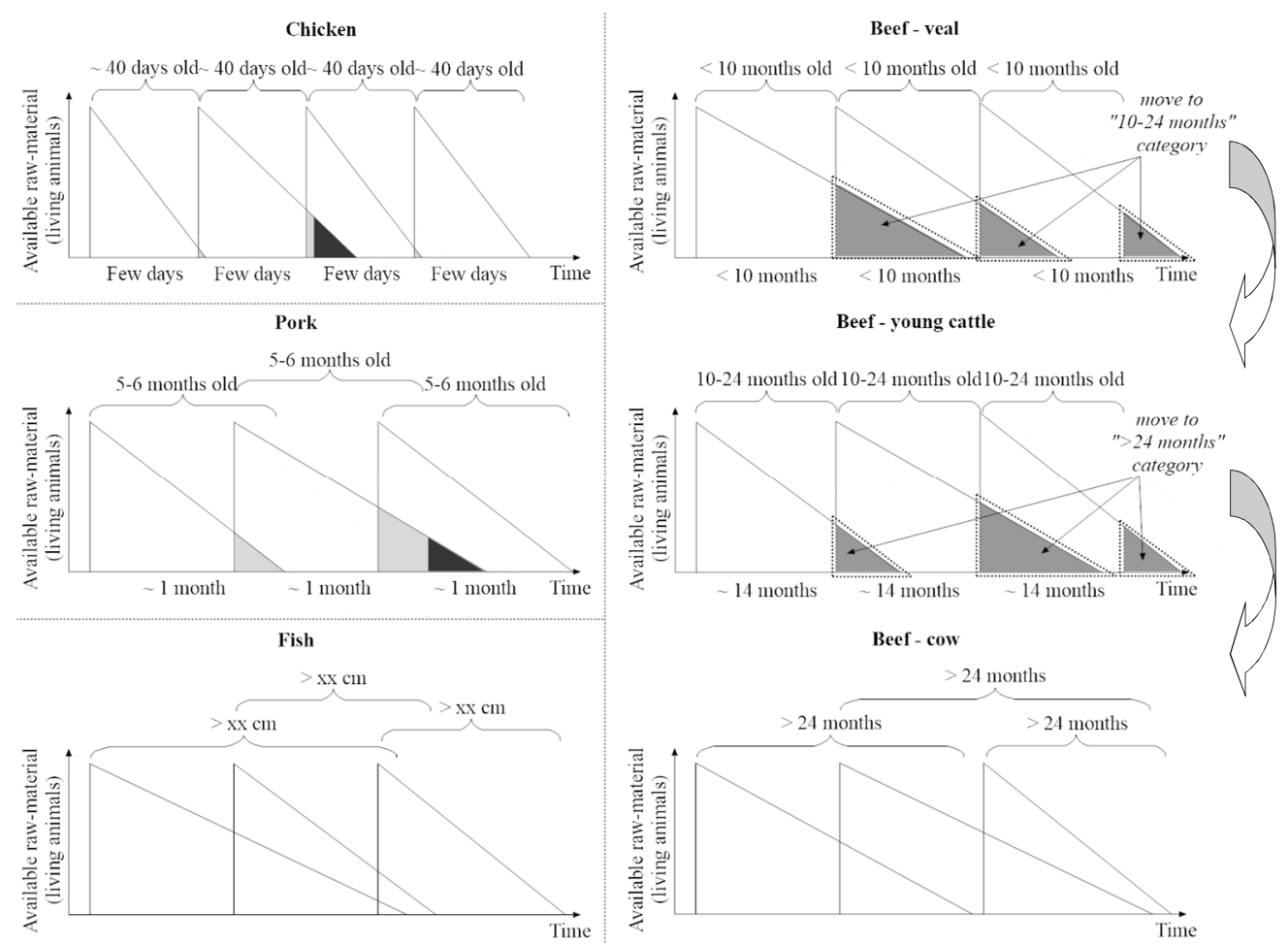

Fig. 4. Time continuum for Planning of Animals and Their Lifetime Window 
In Figure 4, Y-axis is available amount of raw materials for production (i.e. living animals) at a given time, and $\mathrm{x}$-axis indicating the time. The light grey areas are amounts available within time-slack during which the animal's lifetime is acceptable for production, black areas are amounts available when lifetime exceeds upper limit (i.e. animals are too old for production) and dark grey areas are amounts when animals are too old, but suitable for different type of product. From the figure, chicken and pork face the chance of being too old and not fit for production (creating waste) with few days or one-month time-slack, respectively, which enhances the need for accuracy in demand planning. Fish only corresponds to a minimum size when caught and "thebigger-the-merrier"-principle applies (i.e. bigger fish means more products per fish thus greater revenue). Opposite to all meat types, beef animals face a stepwise requirement: if animals are too old for one category (i.e. veal/cattle) they can be used for different product type (i.e. cattle/cow), and when reaching "cow"-step "the-bigger-the-merrier"principle applies.

\section{Discussion \& Conclusion}

One of the main findings is that sharing demand information relatively to the time it takes to raise the animals ready for slaughtering/catching (i.e. animals' lifetime) can allow upstream supply chain to be better prepared for the demand behavior. In turn, this may not only reduce forecast errors from untimely forecast sharing, which influences the service levels from supplier to $\mathrm{ABC}$ to the shops positively and derives higher revenue, it also reduce undesirable noise in the supply chain from premature demand information. Thus, sharing information timely align the upstream production and birth of animals to the real demand behavior. As a consolidator in the supply chain, the wholesaler must be able to interpret and plan to expected level of demand [2], "to be more proactive to anticipated demand and more reactive to unanticipated demand" [12]. From the theoretical framework, the longer time horizon to forecast the greater level of forecast error, meaning that forecasting and demand information sharing should be as timely as possible. By taking into consideration the total time of the product, in particular the animals' lifetime and production time, it is possible to derive the timely point in time, at which forecast should be shared and point in time actual order should be dispatched. That is, just prior to the animals' birth.

In order to ensure the overall efficient and effective demand and supply chain planning and thus encompass the different planning-steps at each supply chain stage (production planning, master production schedule, material requirements planning, capacity planning etc.) - and the time-horizon-related forecast errors, information should be shared with certain time-intervals throughout time, relative to the animals' lifetime. Figure 5 illustrates demand forecasts' error-distributions and their adjustment of mean and median values relatively to the forecasts' time-horizon (the short time-horizon, the smaller error), hence also the risk of over- and undersupply of resources. The dark grey area presents the chance of undersupply and stock out is greater than $100 \%$ service level (i.e. forecast X-n, X-2 and X). Light grey area shows the chance of oversupply and full 
delivery is greatest (i.e. forecast X-3 and X-1). Thus, depending on the individual animal' lifetime (i.e. meat-type), demand forecast(s) should be shared differently through time - i.e. either several (for beef), few times (for pork) or a single time (for chicken). Hence, sharing demand information relatively to animals' lifetime also means later information sharing for chicken products.

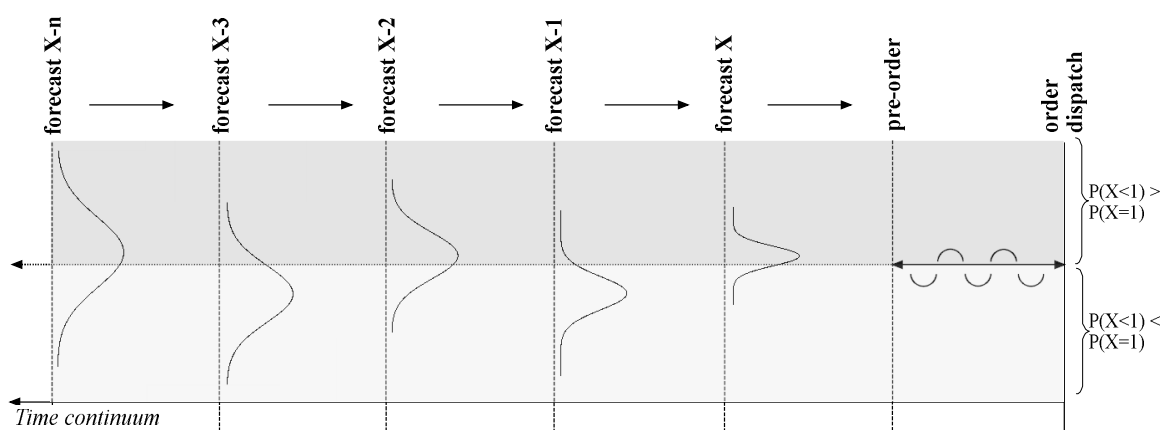

Fig. 5. Forecasting Error Distribution through Time

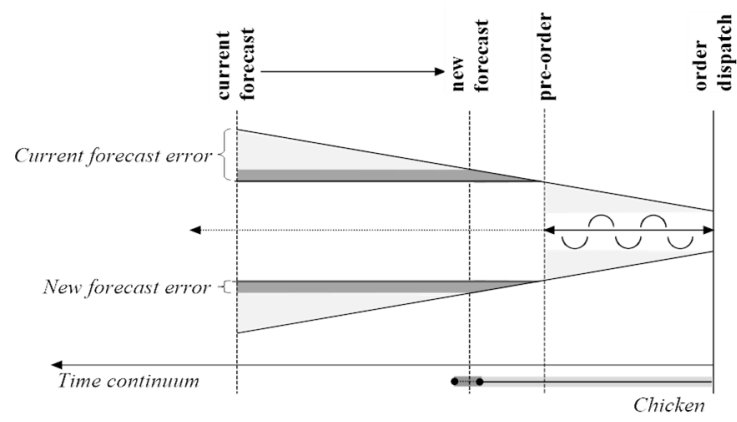

Fig. 6. Reduction in Forecasting Error for Chicken Products

In Figure 6, ABC' current versus suggested point of forecast is shown. Since chickens require 40 days before ready for slaughtering, the postponement of demand sharing (from three months to around 40 days) will reduce errors in estimation and noise in the supply chain. Moreover, this will also reduce the chance of oversupply, and hence the chance of having chickens too old causing waste. For the other meat products, the differentiation is similarly influenced by animals' lifetime. Pork meat requires five to six months to become ready for slaughtering and demand forecast should be shared from around six months before order dispatch and on regular interval up until pre-order. Beef meat type is a stepwise product (veal/cattle/cow) and less sensitive to overestimation. If having too many raw materials (i.e. animals), they can be moved into different category - and when reaching "cow"-category, they follow "the-more-the-merrier"-principle. Fish type follows the "the-more-the-merrier"-principle, and is per se only sensitive to under-estimation since overestimation means greater value (keeping fish alive means bigger fish, hence more products from a single fish), in turn reducing the sensitivity in 
demand planning. Alike pork, demand information about beef and fish should similarly be shared on regular interval prior to order dispatch. From theoretical framework, the interval depends on different factors outside the scope of this paper, hereunder demand fluctuations and demand type.

This research has focused on differentiation for four major products groups in a single case study, and additional research is needed in terms of more product groups, more case companies and testing of suggested approach, to increase level of validity. Other meat-types are seasonal and/or only sold for limited time during a year, which may have influence (products in this study have constant demand throughout year). Also, research should be made in reduction of relative waste amount from having too large amount of products in shops, in regards to differentiated pricing of products when getting closer to expiration date [19] and its influence on demand behavior.

\section{References}

1. Mena, C., Terry, L.A., Williams, A., Ellram, L.: Causes of Waste across Multi-Tier Supply Networks: Cases in the UK Food Sector. Int. J. Prod. Econ. 152, 144-158 (2014).

2. Kuhn, H., Sternbeck, M.G.: Integrative retail logistics: An exploratory study. Oper. Manag. Res. 6, 2-18 (2013).

3. Kaipia, R.: Coordinating Material and Information Flows with Supply Chain Planning. Int. J. Logist. Manag. 20, 144-162 (2009).

4. Romsdal, A.: Differentiated Production Planning and Control in Food Supply Chains. (2014).

5. Entrup, M.L.: Advanced Planning in Fresh Food Industries, Integrating Shelf Life into Production Planning. Physica-Verlag Heidelberg, Berlin (2005).

6. Ivert, L.K., Dukovska-Popovska, I., Kaipia, R., Fredriksson, A., Dreyer, H.C., Johansson, M.I., Chabada, L., Damgaard, C.M., Tuomikangas, N.: Sales and Operations Planning: Responding to the Needs of Industrial Food Producers. Prod. Plan. Control. 26, 280-295 (2015).

7. Kampen, T.J. Van, Akkerman, R, Donk, D.P. Van: SKU Classification: a Literature Review and Conceptual Framework. Int. J. Oper. Prod. Manag. 32, 850-876 (2012).

8. Hanke, J.E., Wichern, D.W.: Business Forecasting. Pearson Prentice Hall, New Jersey (2009).

9. Williams, T.M.: Stock Control with Sporadic and Slow-Moving Demand. J. Oper. Res. Soc. 35, 939-948 (1984).

10. Boylan, J., Syntetos, A., Karakostas, G.: Classification for Forecasting and Stock Control: A Case Study. J. Oper. Res. Soc. 59, 473-481 (2008).

11. Hübner, A.H., Kuhn, H., Sternbeck, M.G.: Demand and Supply Chain Planning in Grocery Retail: an Operations Planning Framework. Int. J. Retail Distrib. Manag. 41, 512-530 (2013).

12. Lambert, D.M.: Supply Chain Management - Processes, Partnership, Performance. Supply Chain Management Institute, Sarasota (2008).

13. Chen, F., Drezner, Z., Ryan, J.K., Simchi-levi, D., Chen, F., Drezner, Z., Ryan, J.K.: Quantifying the Bullwhip Effect in a Simple Supply Chain: The Impact of Forecasting, Lead Times, and Information. Manage. Sci. 46, 436-443 (2000).

14. Adebanjo, D.: Understanding Demand Management Challenges in Intermediary Food Trading: A Case Study. Supply Chain Manag. An Int. J. 14, 224-233 (2009).

15. Fisher, M., Raman, A.: Flexible Supply Chains. In: The New Science of Retailing. pp. 105-131. Harvard Business Press, Boston (2010)

16. Flynn, B.: Empirical Research Methods in Operations Management. J. Oper. Manag. 9, 250-284 (1990).

17. Yin, R.K.: Case Study Research: Design and Methods. SAGE Publications Inc, California (2014).

18. Eisenhardt, K.M.: Building Theories from Case Study Research. Acad. Manag. Rev. 14, 532-550 (1989).

19. Hvolby, H.H., Steger-Jensen, K.: Managing Cannibalization of Perishable Food Products in the Retail Sector. Procedia Comput. Sci. 64, 1051-1056 (2015). 